\title{
Bentonite/Iron Oxide Composites: Preparation and Characterization by Hyperfine Methods
}

\author{
Petr Křišt'an, ${ }^{1}$ Vojtěch Chlan, ${ }^{1}$ Helena Štěpánková, ${ }^{1}$ Richard Řezníček, ${ }^{1}$ Karel Kouřil, ${ }^{1}$ \\ Josef Štěpánek, ${ }^{1}$ Kateřina Poláková, ${ }^{2}$ Vít Procházka, ${ }^{2}$ Jan Čuda, ${ }^{2}$ and Ivo Medřík ${ }^{2}$ \\ ${ }^{1}$ Faculty of Mathematics and Physics, Charles University in Prague, V Holešovičkách 2, 18000 Prague 8, Czech Republic \\ ${ }^{2}$ Palacky University, Šlechtitelu 11, 78371 Olomouc, Czech Republic
}

Correspondence should be addressed to Helena Štěpánková; helena.stepankova@mff.cuni.cz

Received 29 March 2013; Accepted 21 June 2013

Academic Editor: Oleg Petracic

Copyright (C) 2013 Petr Křištan et al. This is an open access article distributed under the Creative Commons Attribution License, which permits unrestricted use, distribution, and reproduction in any medium, provided the original work is properly cited.

\begin{abstract}
Bentonite/iron oxide system is prepared by isothermal calcination of powder composed of bentonite clay and precursor containing ferric acetate. This preparation technique enables one to get the composite material directly, that is, iron oxide particles embedded in a bentonite matrix. Calcination temperature $T_{\text {calc }}$ is varied from $320^{\circ} \mathrm{C}$ to $700^{\circ} \mathrm{C}$. The resulting series of samples is characterized by local methods based on hyperfine interactions: ${ }^{57} \mathrm{Fe}$ nuclear magnetic resonance (NMR) and the Mössbauer spectroscopy. The results show that the phase composition changes significantly in dependence on calcination temperature. The amount of maghemite phase rapidly increases up to $T_{\text {calc }}=420^{\circ} \mathrm{C}$ and decreases abruptly for $T_{\text {calc }}$ higher than $460^{\circ} \mathrm{C}$.
\end{abstract}

\section{Introduction}

Magnetic or superparamagnetic iron oxide particles of submicron and nanoscale dimensions are successfully applied in biomedical and bioengineering applications [1-4]. They are functional, for example, in magnetic resonance imaging (MRI) as contrast agents for diagnostic purposes, for location and tracking of labeled cell or in drug delivery studies. Maghemite $\left(\gamma-\mathrm{Fe}_{2} \mathrm{O}_{3}\right)$ attached to the surface of the bentonite clay forms an efficient negative oral contrast agent for MRI diagnostics in gastroenterology [5] or should be used, for example, for magnetic separation of composite from the medium after sorption processes [6]. In this paper, we report on a bentonite/iron oxide sample series obtained by isothermal calcination of powder composed of bentonite and ferric acetate. The proposed technique enables to prepare directly the composite material of iron oxide particles embedded in a bentonite matrix preventing the particles from aggregation.

The prepared bentonite/iron oxide samples are characterized by two local methods based on hyperfine interactions: ${ }^{57} \mathrm{Fe}$ nuclear magnetic resonance (NMR) spectroscopy and the Mössbauer spectroscopy (MS). Both methods are sensitive to the iron ionic state and environments; however, they differ in sensitivity, resolution, evaluated parameters, accuracy, and certainly in experimental demands and laboriousness. The Mössbauer measurements become a standard method for monitoring of preparation processes of submicron and nanoscale maghemite and related iron oxides; see, for example, [7-9]. On the other hand, maghemite itself, though it is used in MRI, has been studied by NMR [10-14] only rarely.

\section{Materials and Methods}

2.1. Synthesis. Powder composite samples were prepared by thermal decomposition of iron (II), $\left(\mathrm{CH}_{3} \mathrm{CO}_{2}\right)_{2} \mathrm{Fe}$ (Sigma Aldrich) in air. $1000 \mathrm{mg}$ of $\left(\mathrm{CH}_{3} \mathrm{CO}_{2}\right)_{2} \mathrm{Fe}$ was mixed with $2000 \mathrm{mg}$ of bentonite (Tamda-Fagron), and the mixture was homogenized in an agate mortar and then calcined for 1 hour at isothermal conditions at various temperatures $T_{\text {calc }}$ from $320^{\circ} \mathrm{C}$ to $700^{\circ} \mathrm{C}$. The calcinations were done in a porcelain crucible inside a muffle furnace LM 112.27 (Linn High Therm $\mathrm{GmbH})$.

2.2. The Mössbauer Spectroscopy. The room temperature ${ }^{57} \mathrm{Fe}$ Mössbauer spectra were collected in a zero external magnetic 

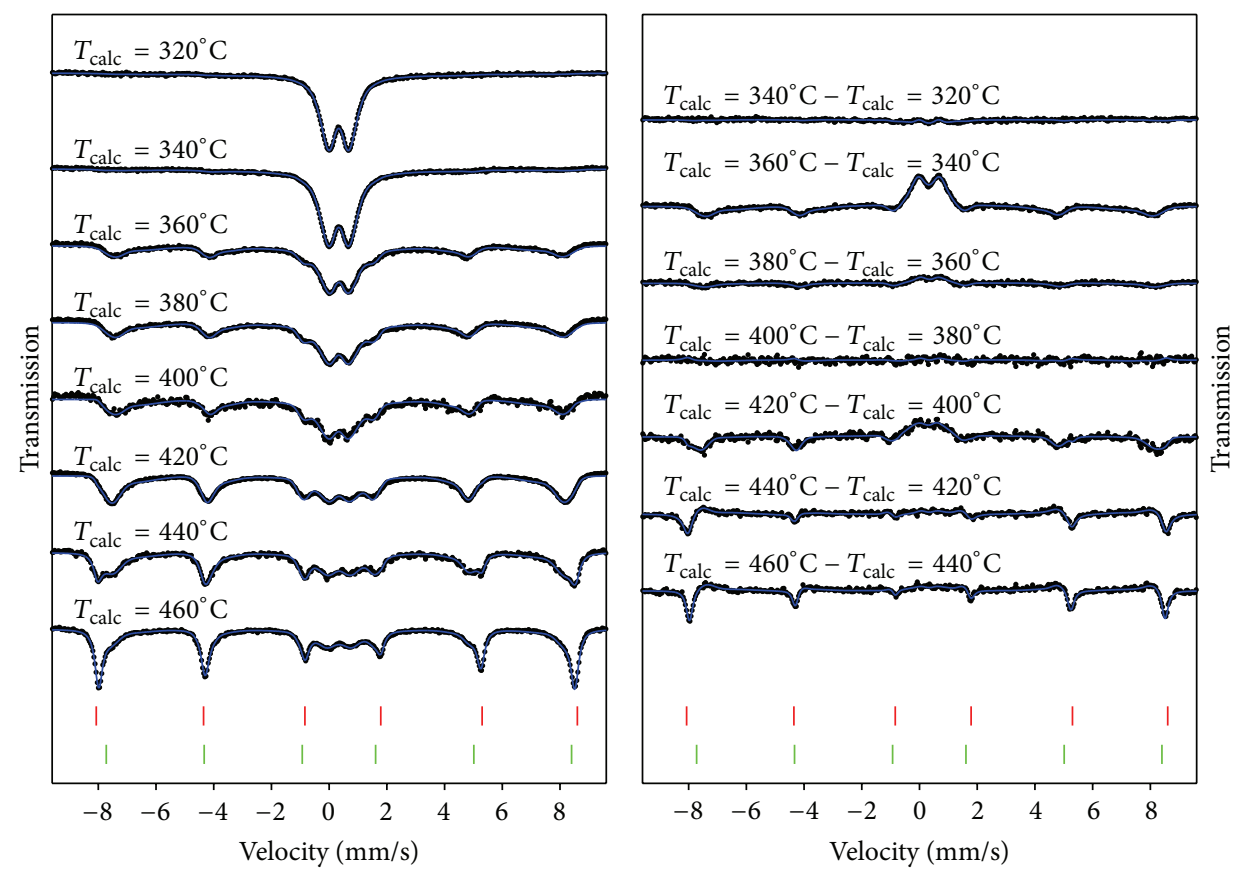

FIGURE 1: Left: the room temperature ${ }^{57}$ Fe Mössbauer spectra measured in zero external magnetic field, experiment (symbols), and fit (lines). Right: differences between the successive spectra. In both parts of the figure, positions of spectral lines in sextets of well-crystallized hematite and maghemite calculated from hyperfine parameters in [7] are marked by short vertical lines (red lines, hematite; green lines, maghemite).

field in the range $(-10,+10) \mathrm{mm} / \mathrm{s}$ using a constant acceleration spectrometer with a ${ }^{57} \mathrm{Co}(\mathrm{Rh})$ source. The velocity scale was calibrated relative to ${ }^{57} \mathrm{Fe}$ in $\alpha$-Fe. The spectra were analyzed by the CONUSS software package [15] and in parallel by our purpose-made software.

2.3. Nuclear Magnetic Resonance. The ${ }^{57} \mathrm{Fe}$ NMR spectra of all samples were recorded in a zero external field at $4.2 \mathrm{~K}$ using the pulse Bruker Avance spectrometer console. The measured sample was fixed in the copper coil of a tuned parallel resonant circuit and submerged in liquid helium. Additional NMR measurements of selected samples were done at room temperature.

A frequency-swept regime was employed with a step of $100 \mathrm{kHz}$. The following parameters were used in a spin echo sequence: pulse duration of $2 \mu \mathrm{s}$ and $4 \mu \mathrm{s}$ for the first and second pulse, respectively, time delay $23 \mu$ s, repetition time $\sim 10 \mathrm{~ms}$, and optimal amplitude of the radiofrequency field was found. In order to reach a sufficient signal/noise $(S / N)$ ratio, 4096 scans were acquired at each frequency. To further increase $S / N$ and verify the impact of nuclear spin-spin relaxation rate on spectral shape, the Carr-PurcellMeiboom-Gill (CPMG) multiecho pulse sequence [16] was applied where all generated echoes in the train were recorded, and coherent summation of selected echoes was done.

Time domain data obtained at each excitation frequency were transformed to frequency domain using fast Fourier transform (FFT), and the final spectrum was plotted as modules of Fourier transform at particular excitation frequencies.

\section{Results and Discussion}

The room temperature Mössbauer spectra of bentonite/iron oxide samples prepared by an annealing process at calcination temperatures $\left(T_{\text {calc }}\right) 320,340,360,380,400,420,440$, and $460^{\circ} \mathrm{C}$ are shown in Figure 1 together with the differences between the successive spectra in the series. Three spectral components can be resolved in the spectral set: a doublet and two sextets. The line positions of the sextets correspond to maghemite $\left(\gamma-\mathrm{Fe}_{2} \mathrm{O}_{3}\right)$ and hematite $\left(\alpha-\mathrm{Fe}_{2} \mathrm{O}_{3}\right)$ [7].

Figure 1 provides a qualitative view of the effect of the calcination temperature. First two samples (calcination at 320 and $340^{\circ} \mathrm{C}$ ) exhibit paramagnetic behavior because a doublet component, representing according to its hyperfine parameters [17] amorphous $\mathrm{Fe}_{2} \mathrm{O}_{3}$, is dominant in their spectra. The other spectra bring out the samples to be a mixture of paramagnetic and magnetically ordered materials. It is evident that the doublet intensity decreases while the maghemite and then the hematite phases are formed when $T_{\text {calc }}$ is increased.

Quantitative determination of the phase composition is complicated by the overlap of the spectral components, namely, of the doublet and the maghemite sextet which can be broadened by a hyperfine field distribution. In order to get proper quantitative evaluation of sample composition in dependence on $T_{\text {calc }}$, a suitable fitting model for spectral analysis is needed. To minimize the influence of systematic errors of particular models, we therefore employed three different decomposition procedures. The first and the second 


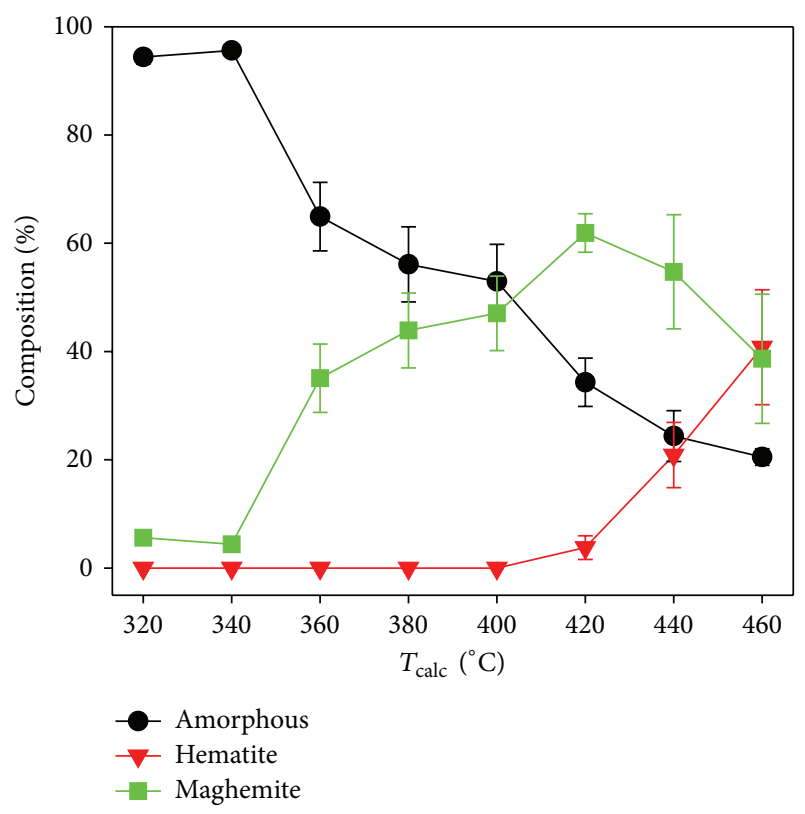

FIGURE 2: Concentration of maghemite, amorphous $\mathrm{Fe}_{2} \mathrm{O}_{3}$, and hematite determined from the Mössbauer spectra.

approaches utilized the CONUSS package, while the third utilized our purpose-made software.

In the first model, the doublet was reconstructed by a distribution of electric quadrupole interaction (quadrupole splitting) corresponding to amorphous $\mathrm{Fe}_{2} \mathrm{O}_{3}$, paramagnetic at the given temperature above the Curie point [17]. The maghemite phase formed during the annealing was associated with a spectral component featuring magnetic dipole interactions with Gaussian distribution of hyperfine magnetic field and very low or zero quadrupole splitting. For the samples prepared at temperature $T_{\text {calc }}=420^{\circ} \mathrm{C}$ and higher, the third spectral component was added which was identified according to its hyperfine parameters (magnetic splitting, isomer shift, and quadrupole splitting) as hematite.

The spectra with magnetite component exhibit asymmetric shape of sextet lines which can be easily seen for samples with $T_{\text {calc }}=420$ and $440^{\circ} \mathrm{C}$.

This behavior is typically determined by the presence of ${ }^{57} \mathrm{Fe}$ nuclei in significantly lower magnetic hyperfine field and assigned to maghemite with not fully developed magnetic structure. The second model then accounted for a broad maghemite sextet, and for this purpose, the first model was amended by fourth component characterized by a large asymmetric distribution that gradually decreased at the side of low hyperfine fields.

The third analysis of the Mössbauer spectra was performed via decomposition into a set of a doublet and two sextets by using a least-square fit. The line shapes of the doublet and the hematite sextet were approximated by the Pearson VII functions. The maghemite spectrum was modelled as a superposition of contributions from ${ }^{57} \mathrm{Fe}$ nuclei in the tetrahedral (A) and octahedral (B) sites of spinel structure (with $3: 5$ intensity ratio and $0.14 \mathrm{~mm} / \mathrm{s}$ difference of isomer

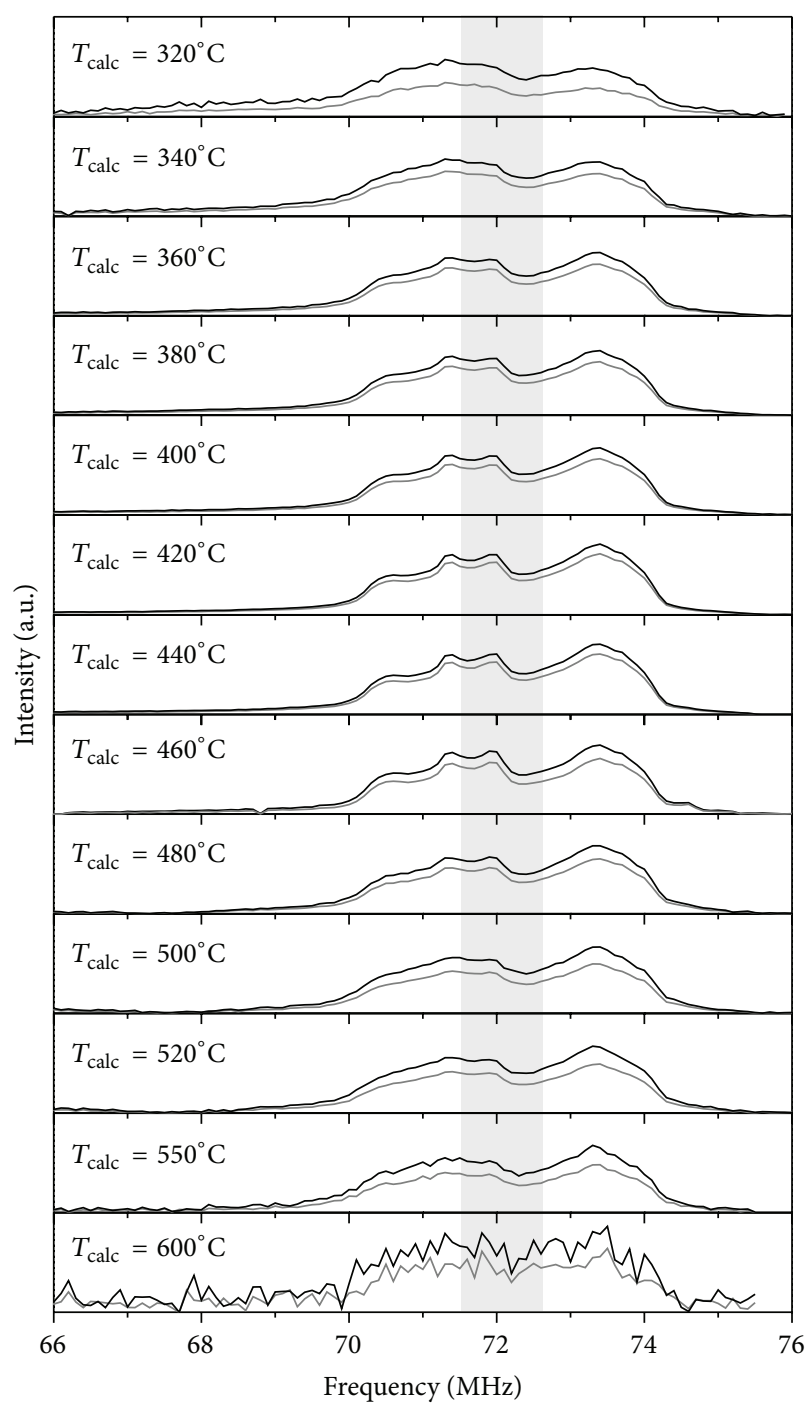

FIGURE 3: NMR spectra of ${ }^{57} \mathrm{Fe}$ (gyromagnetic ratio $1.38 \mathrm{MHz} / \mathrm{T}$ ) in maghemite phase measured at $4.2 \mathrm{~K}$ in zero external magnetic field. Gray spectral area marks superposed signals from ${ }^{57} \mathrm{Fe}$ in $\mathrm{A}$ and $\mathrm{B}$ sites; left parts of the spectra belong to A sites, right part to B sites. (Black lines, the spectra evaluated from echoes 1-10 and normalized to equal areas; grey lines, spectra from echoes 1-21.) Maghemite signals of samples with $T_{\text {calc }}=600^{\circ} \mathrm{C}$ and $700^{\circ} \mathrm{C}$ were very weak due to negligible content of the phase; the latter spectrum is not shown.

shifts [7]). The fit provided the hyperfine field distributions approximated by a sum of two Gaussian curves with different magnitudes, and the position of the lesser one corresponded to a hyperfine field lowered from 10 to $17 \%$ in respect to the main curve. The fitting procedure was primarily applied to the first and the last spectrum of the series and to the differences between subsequent spectra. The decompositions of the original spectra (except the first and the last one) were calculated afterwards. Results of this fit are shown in Figure 1.

Results of the three analyses are slightly different but show similar dependence of the composition on the calcination temperature. The average values of the amorphous, maghemite, and hematite phases amounts are plotted in 


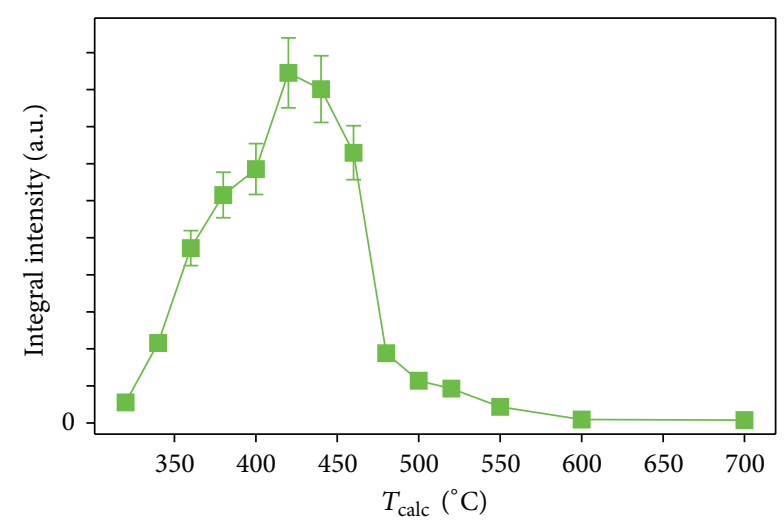

FIgURE 4: Relative amount of maghemite phase in sample series evaluated from NMR in dependence on calcination temperature.

Figure 2 with error bars corresponding to a standard deviation.

Our NMR measurements focused on the spectral region of ${ }^{57} \mathrm{Fe}$ resonance in maghemite phase and monitored spectral shape and intensity in dependence on $T_{\text {calc }}$ from $320^{\circ} \mathrm{C}$ to $700^{\circ} \mathrm{C}$. The spectra recorded at $4.2 \mathrm{~K}$ are shown in Figure 3. The spectra evaluated from echoes 1-10 in comparison with those from echoes 1-21 help to estimate the impact of spinspin relaxation on the spectral shapes and intensities. The spectral shape is almost independent of the number of considered echoes; the nuclear spin-spin relaxation is slowest for $T_{\text {calc }} 400-440^{\circ} \mathrm{C}$.

It is known [10] that subspectra of ${ }^{57} \mathrm{Fe}$ in tetrahedral (A) and octahedral (B) sites in zero external field are partially overlapped, which is marked in Figure 3. Maximal intensity of $\mathrm{B}$ line is at $73.4 \mathrm{MHz}$, and the spectrum of A sites exhibits characteristic features (with three local maxima at $70.50,71.35$, and $71.95 \mathrm{MHz}$ ) which become well resolved for $T_{\text {calc }}$ from 400 to $460^{\circ} \mathrm{C}$. This effect is most likely connected with higher degree of atomic/vacancy ordering in maghemite spinel structure. The maghemite signal intensity rapidly increases up to $T_{\text {calc }}=420^{\circ} \mathrm{C}$, and then, its abrupt decrease appears for $T_{\text {calc }}$ above $460^{\circ} \mathrm{C}$. Evaluation of integral intensities of NMR spectra allowed us to compare the relative amounts of maghemite phase within the sample series. The obtained dependence is shown in Figure 4.

For $T_{\text {calc }}=700^{\circ} \mathrm{C}$, also ${ }^{57} \mathrm{Fe}$ NMR of hematite was measured at $4.2 \mathrm{~K}$. The maximum of hematite spectrum appears at $73.5 \mathrm{MHz}$, in agreement with [18]. In this sample, the signals of hematite and maghemite were of comparable intensities. Separation of the signals was achieved due to difference in enhancement factors which resulted in different optimal excitation conditions: radiofrequency field needed for hematite was approximately an order stronger than that for maghemite (using the same pulse lengths). The hematite signal at $4.2 \mathrm{~K}$ in samples with higher content of maghemite (for lower $T_{\text {calc }}$ ) was most likely buried in strong maghemite contribution. However, hematite signals were detected at room temperature at $\sim 71.1 \mathrm{MHz}$, and the spectral linewidths were of $\sim 0.2 \mathrm{MHz}$.

\section{Conclusions}

Composite bentonite/iron oxide samples were prepared by isothermal calcination of bentonite and precursor containing ferric acetate and were characterized by ${ }^{57} \mathrm{Fe}$ NMR and the Mössbauer spectroscopy. The dependence of the maghemite content on the calcination temperature monitored by both methods is in a reasonable agreement and shows maximum around $T_{\text {calc }}=420^{\circ} \mathrm{C}$. Contents of other iron oxide phases are determined from the Mössbauer spectra, while NMR yields more details of hyperfine magnetic field distribution in well-ordered magnetite phase.

\section{Acknowledgment}

This work was supported by Grant SVV-2013-267303 and the Project no. 392111 of the Grant Agency of the Charles University in Prague.

\section{References}

[1] A. K. Gupta and M. Gupta, "Synthesis and surface engineering of iron oxide nanoparticles for biomedical applications," Biomaterials, vol. 26, no. 18, pp. 3995-4021, 2005.

[2] S. Purushotham and R. V. Ramanujan, "Modeling the performance of magnetic nanoparticles in multimodal cancer therapy," Journal of Applied Physics, vol. 107, no. 11, Article ID 114701, 2010.

[3] S. Mornet, S. Vasseur, F. Grasset, and E. Duguet, "Magnetic nanoparticle design for medical diagnosis and therapy," Journal of Materials Chemistry, vol. 14, no. 14, pp. 2161-2175, 2004.

[4] Q. A. Pankhurst, J. Connolly, S. K. Jones, and J. Dobson, "Applications of magnetic nanoparticles in biomedicine," Journal of Physics D, vol. 36, no. 13, pp. R167-R181, 2003.

[5] K. Kluchová, R. Zbořil, J. Tucek et al., "Superparamagnetic maghemite nanoparticles from solid-state synthesis-their functionalization towards peroral MRI contrast agent and magnetic carrier for trypsin immobilization," Biomaterials, vol. 30, no. 15, pp. 2855-2863, 2009.

[6] Z. Orolinová and A. Mockovčiaková, "Structural study of bentonite/iron oxide composites," Materials Chemistry and Physics, vol. 114, pp. 956-961, 2009.

[7] R. Zboril, M. Mashlan, and D. Petridis, "Iron(III) oxides from thermal processes-synthesis, structural and magnetic properties, Mössbauer spectroscopy characterization, and applications," Chemistry of Materials, vol. 14, no. 3, pp. 969-982, 2002.

[8] J. Tuček, R. Zbořil, and D. Petridis, "Maghemite nanoparticles by view of Mössbauer spectroscopy," Journal of Nanoscience and Nanotechnology, vol. 6, no. 4, pp. 926-947, 2006.

[9] P. Tartaj, M. del Puerto Morales, S. Veintemillas-Verdaguer, T. González-Carreño, and C. J. Serna, "The preparation of magnetic nanoparticles for applications in biomedicine," Journal of Physics D, vol. 36, no. 13, pp. R182-R197, 2003.

[10] S.-J. Lee and S. Lee, "The spin structure of maghemite investigated by ${ }^{57} \mathrm{Fe}$ NMR," New Journal of Physics, vol. 8, article 98, 2006.

[11] T. J. Bastow, A. Trinchi, M. R. Hill, R. Harris, and T. H. Muster, "Vacancy ordering in $\gamma$ - $\mathrm{Fe}_{2} \mathrm{O}_{3}$ nanocrystals observed by ${ }^{57} \mathrm{Fe}$ NMR," Journal of Magnetism and Magnetic Materials, vol. 321, no. 17, pp. 2677-2681, 2009. 
[12] T. J. Bastow and A. Trinchi, "NMR analysis of ferromagnets: Fe oxides," Solid State Nuclear Magnetic Resonance, vol. 35, no. 1, pp. 25-31, 2009.

[13] T. J. Daou, J. M. Greneche, S. J. Lee et al., "Spin canting of maghemite studied by NMR and in-field Mössbauer spectrometry", The Journal of Physical Chemistry C, vol. 114, pp. 8794-8799, 2010.

[14] M. Fardis, A. P. Douvalis, D. Tsitrouli et al., "Structural, static and dynamic magnetic properties of dextran coated $\gamma-\mathrm{Fe}_{2} \mathrm{O}_{3}$ nanoparticles studied by ${ }^{57} \mathrm{Fe}$ NMR, Mössbauer, TEM and magnetization measurements," Journal of Physics Condensed Matter, vol. 24, no. 15, Article ID 156001, 2012.

[15] W. Sturhahn and E. Gerdau, "Evaluation of time-differential measurements of nuclear-resonance scattering of x rays," Physical Review B, vol. 49, no. 14, pp. 9285-9294, 1994.

[16] S. Meiboom and D. Gill, "Modified spin-echo method for measuring nuclear relaxation times," Review of Scientific Instruments, vol. 29, no. 8, pp. 688-691, 1958.

[17] L. Machala, R. Zbořil, and A. Gedanken, "Amorphous iron(III) oxide-a review," Journal of Physical Chemistry B, vol. 111, no. 16, pp. 4003-4018, 2007.

[18] S.-J. Lee, H. Jung, S. Lee, and J. Dho, "Superparamagnetic behaviour of reentrant weak-ferromagnetic phase in haematite crystal at low temperatures," New Journal of Physics, vol. 11, Article ID 023020, 2009. 

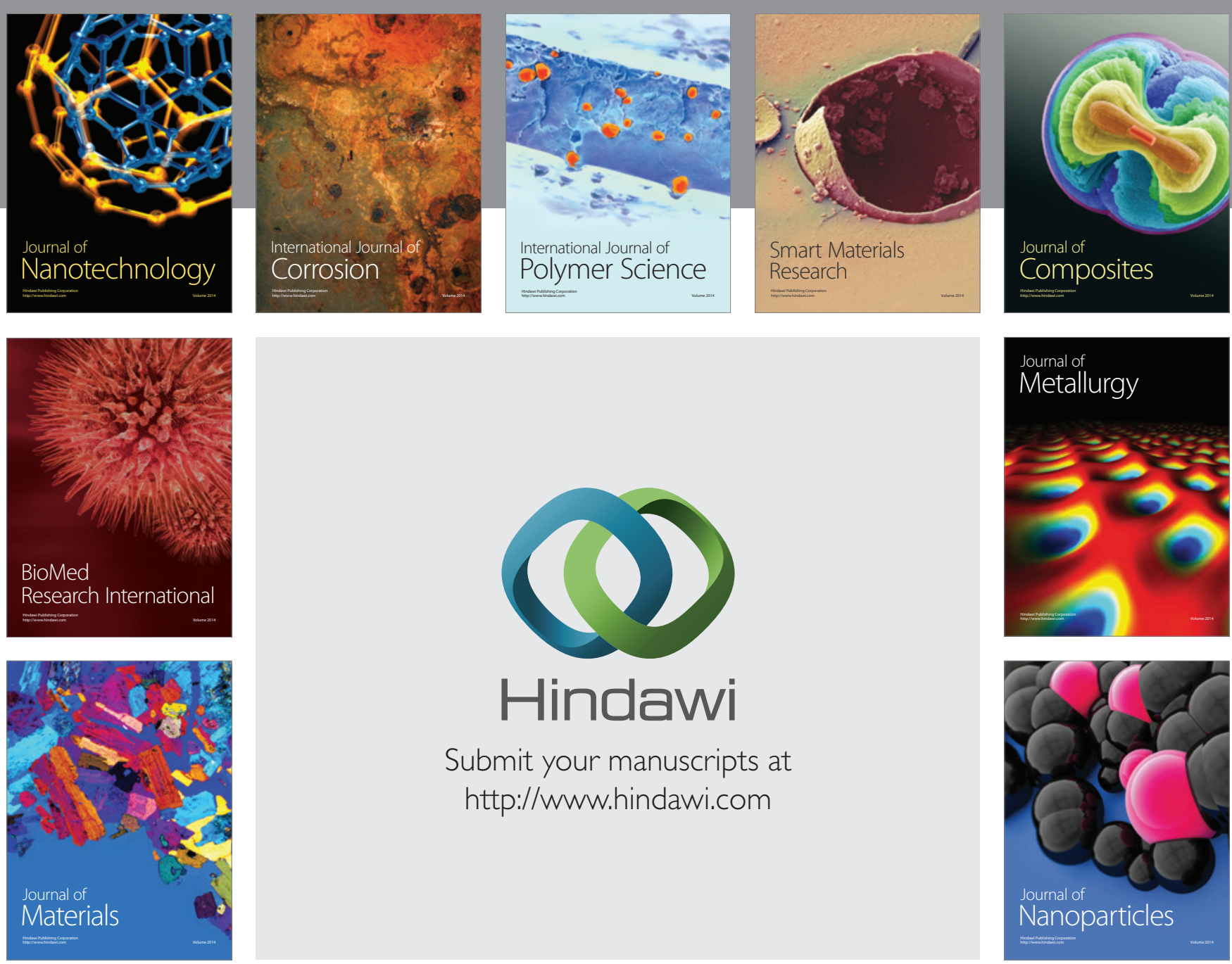

Submit your manuscripts at http://www.hindawi.com
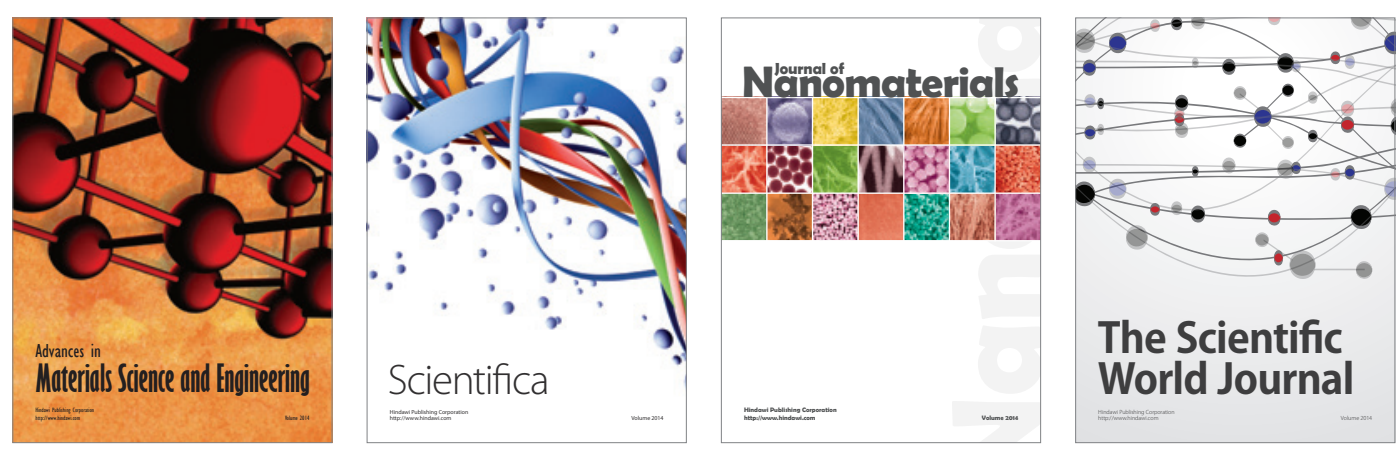

\section{The Scientific World Journal}
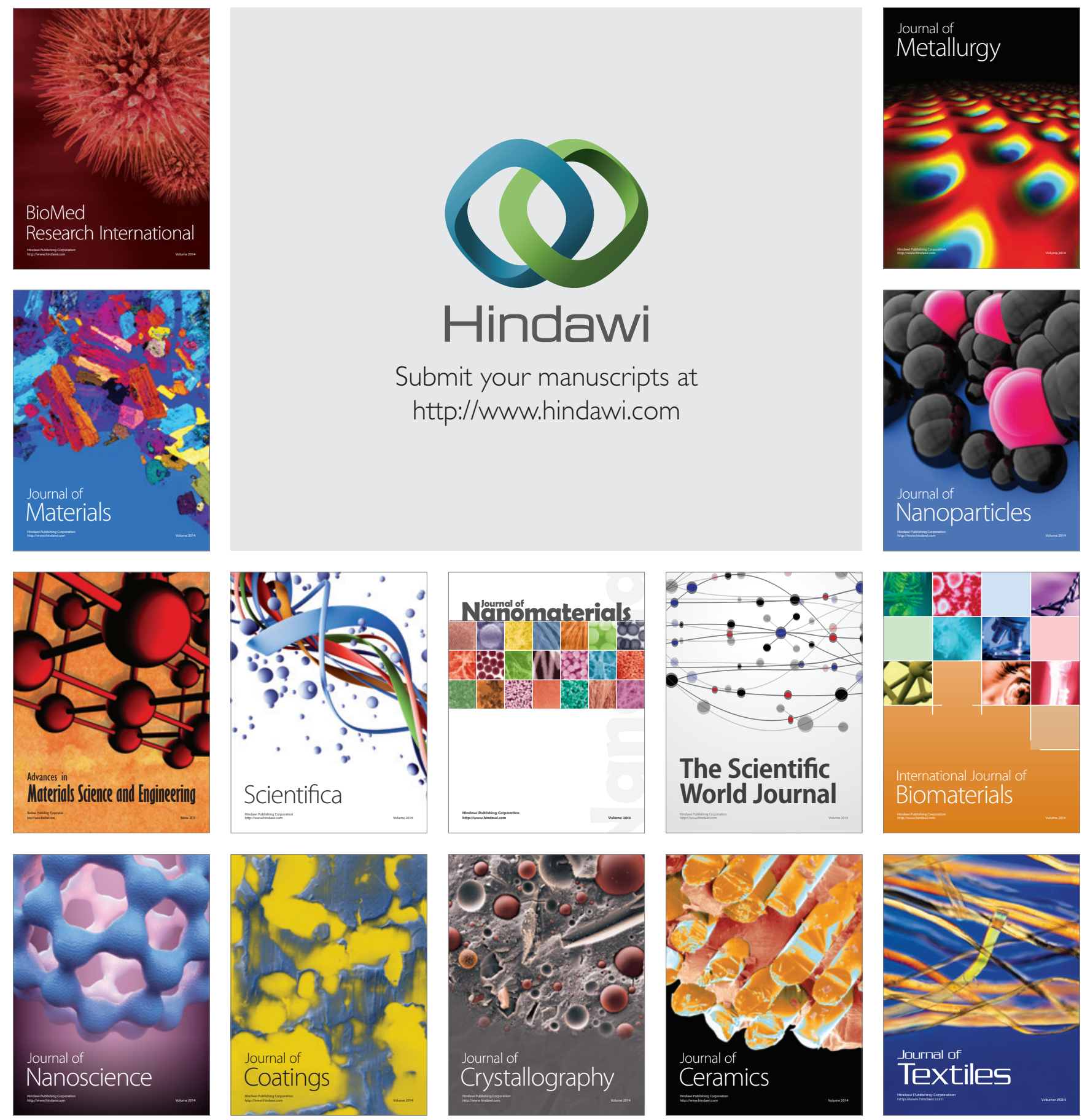